\title{
Knowledge, Attitudes, and Practices Towards Avian Influenza Among Students of Two Public Universities of Surabaya, East Java, Indonesia
}

\section{Saifur Rehman}

Division of Veterinary Public Health Faculty of Veterinary Medicine Universitas Airlangga, Surabaya Indonesia

\section{Fedik Rantam}

Laboratory of Virology and Immunology Division of Microbiology, Faculty of Veterinary Medicine Universitas Airlangga, Surabaya Indonesia

\section{Muhammad Khan}

Department of Epidemiology and Public Health University of Veterinary and Animal Sciences Lahore, Pakistan

\section{Aamir Shehzad}

Laboratory of Virology and Immunology Division of Microbiology, Faculty of Veterinary Medicine Universitas Airlangga, Surabaya Indonesia

\section{Mustofa Effendi ( $\sim$ mhelmieffendi@gmail.com )}

Division of Veterinary Public Health Faculty of Veterinary Medicine Universitas Airlangga, Surabaya Indonesia

\section{Research Article}

Keywords: Knowledge, Avian influenza, Public health, Zoonosis, Indonesia

Posted Date: November 17th, 2021

DOI: https://doi.org/10.21203/rs.3.rs-1018842/v1

License: (c) (1) This work is licensed under a Creative Commons Attribution 4.0 International License. Read Full License 


\section{Abstract}

\section{Background and objectives:}

Avian influenza is a highly contagious disease that causes respiratory failure and has significant public health implications due to its zoonotic potential. Humans are frequently affected after coming into contact with infected birds, body fluid droplets such as those produced during defeathering operations, or other contaminated objects. This study aimed to appraise the students' knowledge, attitudes, and practices (KAPs) related to avian influenza in Surabaya, East Java, Indonesia.

\section{Methods}

Among the students, 300 were interviewed to collect their knowledge about avian influenza and its zoonotic importance. The study population comprised students studying at two public universities having an age range of $<20-50$ years.

\section{Results}

Of the 300 respondents, $97.7 \%$ and $92.3 \%$ were aware of the term avian influenza contagious infection and its pathogenicity related to zoonotic potential. Correlations show that the student's educational status was positively associated with knowledge of animal-to-animal transmission of avian influenza ( $p$ $<0.039$ ). More than $80-90 \%$ of participants had knowledge that infected poultry and birds act as a potential source of avian influenza infection. More than $75 \%$ of the participants suspect poultry workers, butchers and veterinarians were at high risk of avian influenza infection. Fifty-seven percent of the students were not consulted to the doctor whenever they feel influenza-like symptoms. Washing of hands before and after eating a meal and covering of nose during coughing and sneezing were common. Our study results delineated the association of contagious infection of avian influenza transmission to poultry workers after contact with infected birds $(p<0.004)$.

\section{Conclusion}

Our study indicated that the knowledge, attitude, and practices of avian among the students were high, which might provide scientific support to the Indonesian government in developing strategies and public health campaigns among the general population to reduce the disease incidence.

\section{Introduction}

Avian influenza, also known as bird flu, is an infectious disease of birds similar to influenza or flu in humans. It is caused by influenza A virus of which, the subtype H5N1 is highly contagious and is of zoonotic importance. Among this subtype, the highly pathogenic strain referred to as highly pathogenic 
avian influenza virus of type A of the subtype H5N1 (HPAl-A (H5N1)) is highly pathogenic and is highly transmissible to birds due to its airborne transmission potential [1]. It is enzootic to many African, Asian and European bird populations. The introduction of the HPAI H5N1 virus in southern China in the mid1990s, followed by its continental spread across East and Southeast Asia, and the unprecedented outbreaks documented in 2003-2004 is the most emblematic examples of this impact. Recently (from 2014 to 2017), many HPAl subtypes (including H5N1, H5N6, and H5N8) arose in East Asia and spread intercontinentally, emphasizing the critical importance of this geographical hotspot as a source of novel HPAl subtypes [2, 3]. The first human influenza outbreak was documented in Hong Kong in 1997, and by late 2003, it had spread to poultry and caused human deaths in nearly eight East Asian countries, including China, Cambodia, Vietnam, Indonesia, and Thailand [4-6]. The first outbreak of the H5N1 subtype HPAI virus was identified in Indonesia in December 2003, affecting all provinces of Indonesia except one province. The H5N1 virus was first introduced to Java and soon spread to other parts of the country [7]. So far, AIV is a big problem in Indonesia's poultry industry. The outbreak was so fatal that it killed more than 16 million poultry and damaged Indonesia's poultry industry [8-10]. In addition, >860 laboratory-confirmed human cases of HPAI H5N1 have been reported to the World Health Organization (WHO). In Indonesia, 200 laboratory-confirmed human cases of avian influenza A(H5N1) have been reported, with a case-fatality rate of $84 \%$, which is higher than the current global case-fatality rate of $53 \%$ [11]. The zoonotic potential of HPAl is a global public health concern, particularly in preventing a potential pandemic [11]. To stop the virus from spreading, effective prevention and risk management were implemented. These may include culling contaminated and exposed poultry, quarantining infected areas, and active and continuous monitoring of disease signs and mortalities in poultry and pigs [12, 13]. Knowledge, attitude, and practices (KAPs) against a specific disease or illness are amongst the most important aspects in managing and preventing the disease from spreading to the general public $[14,15]$. The adherence to the preventive measures was shown to be associated with the level of knowledge on the disease, especially on routes of transmission and clinical characteristics [16]. According to previous KAP studies on avian flu around the world, most people in endemic countries like China, India, Nepal, Egypt, Thailand, and Cambodia had a higher level of knowledge and understanding about avian flu than people in countries with low or no case of avian flu [17-26]. Furthermore, people that live in high-risk areas were more concerned about their preventive measures and activities in the context of avian flu $[21,23,27$, 28]. As a result, preventing the spread of the disease and raising public awareness about the pandemic are necessary. Protective behaviours and practices were aimed to prevent and reduce the burden of AIV. Infected countries such as Thailand, China, Italy, Turkey, and Afghanistan have been studying KAP's effects on Al in past few years. However, there was a lack of study on the KAP of Al in Indonesia. Nonetheless, a survey of students from various departments at public universities was conducted in response to assess the knowledge and behavioral among educated Indonesian adults regarding avian influenza. As a result, the current study's findings would significantly lead to enhanced medical services for Indonesian people.

The aim of this study is to evaluate the level of knowledge, attitudes, and practices towards avian influenza among university students. They were questioned about their knowledge of Al, their attitude 
towards the disease's prevalence, and their efforts to control the disease. The findings of this study are expected to provide useful information about KAP of AIV to policymakers at this critical time of Covid-19.

\section{Materials And Methods Study area:}

East Java, Indonesia's rugged province, includes Madura, some of the coastal towns, and the eastern part of Java. The total area of East Java is $47,800 \mathrm{Km}^{2}$ and the total population is 38.85 million East Java within the south-central region of Indonesia and an important hub of social lifestyle. Surabaya is the capital city located within the northern coastal part of the province of East Java Indonesia.

An online and offline survey was conducted among the students of two public universities (Universitas Airlangga and Universitas Wijaya Kusuma) in Surabaya.

\section{Study duration}

This KAP survey of Al was conducted from March 1 to April 10, 2021. During this period, data was collected among the students from two different public universities of Surabaya East Java Indonesia.

\section{Study population}

This cross-sectional study was conducted among 300 university students having an age range between $<20-50$ years. from different departments of two public universities of Surabaya. Participants' inclusion criteria were students from two universities who lived in Surabaya. Participants were chosen for the study by approaching them offline in their hostels and laboratories, as well as online through social media by providing online link. We distributed our online survey form together with a quick response (QR) code via direct deliberation in laboratories, online lectures and lecture homepages, university club mailing lists, and social networks. Before filling out the form, all participants provided informed electronic consent to anonymously participate in the study and permitted researchers to use the data. Students from all departments, regardless of age or gender, were eligible to participate in this research.

\section{Data collection and statistical analysis}

Data was collected from March 1 to April 10, 2021, by circulating a questionnaire with informed consent to over 400 participants both offline (140) and online (260), and receiving feedback from 300 of them (offline 140 , online 160 ) respectively. The response rate was $75 \%$ that is $300 / 400$. We used a standardized questionnaire to collect information about the students' avian influenza knowledge, attitude, and practices which were obtained from the published article of Ibrahim et al. [13] and permission was also taken by the corresponding author for its use in the current study. The questionnaire was translated 
into the local language (Bahasa Indonesia) to reduce the possibility of erroneous responses from respondents. The translation and back translation of the questionnaire was done according to the advice of WHO [29]. The figure 1 revealed that questionnaire was divided into four sections. The first section concentrated on the respondents' socio-demographic characteristics. The second section of the questionnaire gathered information about avian influenza knowledge. The third section was mostly concerned with attitudes, while the fourth and final sections were concerned with their practices towards avian influenza prevention (figure 1). The standardized questionnaire took around 10 to $15 \mathrm{~min}$ to complete. The primary author entered the collected data into the Statistical Package for Social Sciences (SPSS) version 25.0. Typing mistakes were identified and rectified. The Chi-square test and the independent t-test were used to examine categorical and continuous data, respectively.

\section{Ethical consideration:}

In the current study all procedural steps for the data collection and keeping information of the participants secret were approved by the Ethical Committee of the University of Airlangga Surabaya vide approval No: 1.KE.028.03.2021.

\section{Guidlinens:}

All methods were carried out in accordance with relevant guidelines and regulations. We comprehensively reviewed the literature to identify published KAP questionnaires about the KAPs of avian influenza in the general population. We have applied the avian influenza related search syntax. We also searched conference papers in the Conference Proceedings Citation Index-Science (CPCI-S) as well as the reference list of relevant studies. Subsequently, we generated a questionnaire (questions or statements) about 3 dimensions: knowledge, attitudes, or practices towards avian influenza. Questionnaires were used following the WHO guidelines, publications and consultation with experts. Developed questionnaires were pre-tested through sharing with respondents to check the validity and reliability of the content. Questionnaire acceptability was determined by Calculation of response rate and percentage of unanswered questions by 400 adults.

\section{Results}

\section{Demographic Charateristics of study participants}

Results showed that both male and female students had a good understanding of AIV.

Gender, age, qualification, hometown, and universities are some of the sociodemographic characteristics studied here. Out of the 300 participants, $38.7 \%(n=116)$ were

males, while $61.3 \%(n=184)$ were females. There were $27 \%(n=83)$ of the respondents under the age of $20,70.7 \%(n=212)$ individuals between the ages of 20 and 30, and small proportion of $1.7 \%(n=5)$ 
respondents between 31 and 50 years of age respectively.

Their educational backgrounds were as follows: 13\% ( $n=39)$ were diploma holder, $83.7 \%(n=251)$ were undergraduate, $2.7 \%$ (8) through masters and $2 \%(0.7)$ post graduated. Fifty five percent $(n=165)$ belong to city while $45 \%(n=135)$ hometown was village. Aside from that, $79 \%(n=237)$ of the individuals were from Universitas Airlangga and 21\% ( $n=63)$ from Universitas Wijaya Kusuma (Table 1).

Table 1

Demographic characteristics of study participant $(n=300)$

\begin{tabular}{|c|c|c|c|}
\hline Variables & Demographic character & Frequency & Percentage \% \\
\hline \multirow[t]{2}{*}{ Gender } & Male & 116 & 38.7 \\
\hline & Female & 184 & 61.3 \\
\hline \multirow[t]{3}{*}{ Age } & $<20$ year & 83 & 27.7 \\
\hline & 20-30 year & 212 & 70.7 \\
\hline & $31-50$ year & 5 & 1.7 \\
\hline \multirow[t]{4}{*}{ Qualification } & Diploma & 39 & 13 \\
\hline & Undergraduate & 251 & 83.7 \\
\hline & Master & 8 & 2.7 \\
\hline & Post graduate & 2 & 0.7 \\
\hline \multirow[t]{2}{*}{ Home Town } & Urban & 165 & 55 \\
\hline & Rural & 135 & 45 \\
\hline \multirow[t]{2}{*}{ Universities } & Universitas Airlangga & 237 & 79 \\
\hline & Universitas Wijaya Kusuma & 63 & 21 \\
\hline
\end{tabular}

\section{Perception about avian influenza}

Among the participants, $97.7 \%(n=293)$ were aware of the term and concept of avian influenza. Similarly, a large proportion of $92.3 \%(n=277)$ considered avian influenza is caused by High pathogenic subtype H5N1 as a zoonotic disease. Almost $62.5 \%(n=187)$ were aware of the signs and symptoms of avian influenza similar to swine influenza. Regarding the mode of transmission, 86.0\% $(n=258)$ said that Al transmitted animals to humans, $48.7 \%(n=146)$ considered that it also transmitted humans to humans. More than half of the $55.7 \%(n=167)$ study participants considered that avian influenza was transmitted by handling uncooked poultry, 30\% $(n=91)$ responded that uncooked eggs are also a source of avian influenza transmission. Thirty-seven percent $(n=119)$ of respondents believe that uncooked frozen poultry can spread avian influenza. Regarding the vehicles of transmission, 89.7\% $(n=269)$ of the participant were awared that poultry and $91 \%(n=273)$ other birds act as vehicles of transmission of AIV. The majority of participants (78-93\%) were awared that poultry workers, butchers, and veterinarians were 
at high risk of contracting the disease as compared to hunters. Regarding the question related to the risk group of AIV infection $96.3(n=289)$ answered that poultry workers were more affected, while $78 \%(n=$ 234) responded that butchers were most affected, $54.7 \%(n=164)$ responded that hunters were also at risk of infection. Out of 300 respondents, $78.3 \%(n=235)$ were answered that veterinarians were at high risk of getting AIV infection (Table 2). 
Table 2

Knowledge of participants about avian influenza $(n=300)$

\section{Study instruments}

\section{Definition of Al}

Avian influenza is a contagious infection

It is caused by the highly pathogenic influenza A (H5N1) virus

Avian influenza is similar to swine influenza regarding its signs and symptoms

\section{Mode of transmission}

Animal-to-human

Animal-to-animal

Human-to-human

Touching uncooked poultry

Touching uncooked eggs

Touching uncooked frozen poultry

\section{Vehicles of transmission}

Poultry

Birds

Other animals

\section{Risk groups}

Poultry workers

Butchers

Hunters
True $\mathrm{n}$

(\%)

293

(97.7)
False $\mathrm{n}$

(\%)

$3(1)$

4 (1.3)

$19(6.3)$

(92.3)

187

(62.3)

$26(8.7) \quad 87(29)$
279

(93)

258

(86)

146

(48.7)

167

(55.7)

112

(37.3)

91

(30.3)
$13(4.3) \quad 8(2.7)$

$26(8.7) \quad 16(5.3)$

106

(35.3)

48 (16)

56 (18.7)

(25.7)

118

(39.3)

70 (23.3)

129

(43)

$80(26.7)$
Don't know n (\%)

4 (1.3)

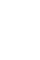




\begin{tabular}{|llll|}
\hline Study instruments & $\begin{array}{l}\text { True n } \\
(\%)\end{array}$ & $\begin{array}{l}\text { False } \mathbf{n} \\
(\%)\end{array}$ & $\begin{array}{l}\text { Don't know } \mathbf{n} \\
(\%)\end{array}$ \\
\hline Veterinarians & $\begin{array}{l}235 \\
\text { (\%) }\end{array}$ & $\begin{array}{l}34 \\
(11.3)\end{array}$ & $31(10.3)$ \\
\hline
\end{tabular}

\section{Attitudes regarding avian influenza}

Table 3 of the current study results describes the participants' attitudes toward Al prevention. Of the total $300,89.7 \%(n=269)$ practiced washing of hands before eating, $69 \%(n=207)$ said that they wash their hands before touching raw poultry meat while $79.7 \%(n=239)$ said that they do the same practiced after touching the raw poultry meat. Regarding using gloves when preparing raw poultry meat $73 \%(n=219)$ said that it's a good practice. Regarding building up good body resistance against the disease, $63.3 \%$ $(n=190)$ said that eating a balanced diet and $70 \%(n=210)$ answered that regular exercise is also an important factor for developing a good body immunity. Furthermore, $232(77 \%)$ to 237 (79\%) participants strongly agree that good personal and environmental hygiene is important to maintain good health and body immunity. 
Table 3

An attitude of participants toward the prevention of avian influenza $(n=300)$

$\begin{array}{llllll}\text { Study instrument } & \begin{array}{l}\text { Strongly } \\ \text { agree }\end{array} & \text { Agree } & \text { Uncertain } & \text { Disagree } & \begin{array}{l}\text { Totally } \\ \text { disagree }\end{array} \\ & \mathbf{n}(\%) & \mathbf{n}(\%) & \mathbf{n}(\%) & \mathbf{n}(\%) & \mathbf{n}(\%)\end{array}$

We wash our hands with soap

Before eating

269

(89.7)

Before touching raw poultry meat

After touching raw poultry meat

good hygienic practice

Preparing raw poultry and other foods using different knives is a good practice

We should clean the cutting boards after preparing raw poultry meat

207 (69)

239

(79.7)

$219(73)$

182

(60.7)

214

(71.3)
$29 \quad 2(0.7)$

(9.7)

\begin{tabular}{llll}
$\begin{array}{l}69 \\
(23)\end{array}$ & $18(6)$ & $3(1)$ & $3(1)$ \\
\hline 52 & $5(1.7)$ & $2(0.7)$ & $2(0.7)$ \\
$(17.3)$ & & &
\end{tabular}

69

$11(3.7) \quad 1(0.3)$

89

(29.7)

$26(8.7)$

$3(1)$

78

(26)

$8(2.7)$

\section{We need to build up good body resistance through}

$\begin{array}{lllll}\text { Balance diet } & \begin{array}{l}190 \\ (63.3)\end{array} & \begin{array}{l}94 \\ (31.3)\end{array} & 14(4.7) & 2(0.7) \\ \text { Regular exercise } & 210(70) & \begin{array}{l}85 \\ (28.3)\end{array} & 5(1.7) & -\end{array}$

We need to maintain

\begin{tabular}{llll} 
Good personal hygiene & $237(79)$ & $\begin{array}{l}61 \\
(20.3)\end{array}$ & $2(0.7)$ \\
Good environmental hygiene & \multicolumn{3}{|c}{} \\
& 232 & 67 & $1(0.3)$ \\
& $(77.3)$ & $(22.3)$ &
\end{tabular}

\section{Practices regarding avian influenza}

In the current research, Table 4 depicted the participants' activities about Al prevention. Out of 300, 73.3\% $(n=220)$ participants reveal that they wash their hands with soap all the time before and after eating. Seventy-eight percent $(n=236)$ of individuals said that they cover their nose during sneezing and $58.7 \%$ $(n=176)$ said that they follow these precautionary measures during coughing. More than half $54 \%(n=$ 162) of the study participants said that they wear the surgical mask all the time if they have symptoms like coughing, runny nose, and sore throat. Out of 300 , only $32 \%(n=97)(32 \%)$ respondents answered that they consult with the doctor when feeling influenza-like symptoms. 
Table 4

Practices of the participants regarding the prevention of $\mathrm{Al}(\mathrm{n}=300)$

\begin{tabular}{|llll|}
\hline Study Instrument & Responses & \\
\hline Question & All the time & Sometime & Never \\
& $\mathbf{n}(\%)$ & $\mathbf{n}(\%)$ & $\mathbf{n}(\%)$ \\
\hline Do you wash hands with soap before eating? & $220(73.3)$ & $79(26.3)$ & $1(0.3)$ \\
\hline Do you wash hands with soap after eating? & $220(73.3)$ & $74(24.7)$ & $6(2)$ \\
\hline Do you cover your nose and mouth when & & & \\
\hline Sneezing & $236(78.7)$ & $57(19)$ & $7(2.3)$ \\
\hline Coughing & $176(58.7)$ & $112(37.3)$ & $12(4)$ \\
\hline When you have influenza-like symptoms such as cough, runny nose, and sore throat & $124(41.3)$ & $14(4.7)$ \\
\hline Do you wear a surgical mask? & $162(54)$ & $171(57)$ & $32(10.7)$ \\
\hline Do you consult the doctor promptly? & $97(32)$ & $125(41.7)$ & $118(39.3)$ \\
\hline Do you live very closely with poultry? & $57(19)$ & 125 & \\
\hline
\end{tabular}

\section{Risk-factors analysis of avian influenza}

Calculations showed a correlation between female gender and knowing about the transmission of avian influenza between animal to animal $\left(X^{2}=7.103, p=0.029\right)$. A similar correlation was noted between gender and wearing of a surgical mask $\left(X^{2}=6.126, p=0.047\right)$. A significant correlation was observed between gender and washing of hands before and after eating $\left(X^{2}=23.208, p=0.001\right)$. A similar correlation was found between graduation level, as educational status and knowledge of risk of avian influenza infection to the veterinarian $\left(X^{2}=23.115, p=0.001\right)$ and butchers $\left(X^{2}=12.563, p=0.051\right)$. Chisquare showed: $\left(X^{2}=14.990, p=0.020\right)$ a significant correlation between graduation level, educational status, and using of surgical mask. There was also a statistically significant association $\left(X^{2}=12.430, p\right.$ $=0.053$ ) between educational status with knowing about the washing of hands to prevent disease transmission (Table 5). 
Table 5

Chi-square analysis of associated risk factors

\begin{tabular}{|llll|}
\hline Question & $\mathrm{X}^{2}$ & $\boldsymbol{p}$-value & $\mathrm{df}$ \\
\hline Correlation between gender and animal to the animal transmission of AIV & 7.103 & 0.029 & 2 \\
\hline Correlation between gender and wearing of surgical mask & 6.126 & 0.047 & 2 \\
\hline Correlation between gender and washing of hands before and after eating & 23.208 & 0.001 & 2 \\
\hline Correlation between educational levels and risk of AIV to the veterinarian & 23.115 & 0.001 & 6 \\
\hline Correlation between educational levels and risk of AIV to butchers & 12.563 & 0.051 & 6 \\
\hline Correlation between educational levels and using of surgical mask & 14.990 & 0.020 & 6 \\
\hline
\end{tabular}

We used an independent sample t-test to determine the correlation between avian influenza contagious infection and its transmission from animal to human; we found $t=-2.481, p=0.009$, showing a significant correlation. An independent t-test demonstrated the effectiveness $t=-3.313 p=0.004$ of avian influenza contagious infection to poultry workers (Table 6). Figure 2. Responses regarding Knowledge attitude and practices

Table 6 Independent sample t-test analysis of associated risk factors

\begin{tabular}{|llll|}
\hline Question & t-test & $p$-value & df \\
\hline Effectiveness AIV contagious on animal to human & -2.645 & 0.009 & 294 \\
\hline Effectiveness of AIV contagious on poultry workers & -3.313 & 0.004 & 294 \\
\hline
\end{tabular}

\section{Discussion}

This study aimed to provide information on Al-related knowledge, attitudes, and practices among university students in Surabaya Indonesia. Human cases of avian influenza (H5N1) have resulted from contact between humans and infected backyard poultry [30]. The frequency of disease occurrence in the avian population is also related to increased risk to humans [31].

In our study, $97.7 \%$ of participants had knowledge about avian influenza, which is comparable to a similar study already conducted in North Africa revealed that the people who kept backyard poultry breeders in rural Egypt's Fayoum Governorate had a high level of knowledge regarding AI [32]. In a study conducted by Khan et al. (2008) on new arrival students' knowledge of avian influenza, $70 \%$ of the students stated that Al is a disease of viral etiology [33]. In contrast, a study conducted in Thailand's Suphan Buri Province found that the majority of respondents had limited knowledge about Al [34, 35]. According to a study conducted in Europe found that a significant number of people lacked a detailed understanding of $\mathrm{Al}$ [36]. The level of awareness in the current study was as high as expected because 
survey respondents were very acquainted with Al due to the high occurrence in the study area and appropriate information regarding the disease.

However, in our findings, 187 (62.3\%) respondents had said that Al and swine influenza had a similarity in signs and symptoms. In an earlier study conducted in China by Gong et al. (2014) found that symptoms and transmission routes of avian influenza differed by area, with Hangzhou having the highest percentage of participants who were aware of AIV symptoms and transmission routes [37].

From the t-test, our study has indicated that respondents were awared with contagious infection of avian influenza from animal to human and poultry workers. Therefore, it is urgent to educate entire communities about the contagious infection of AIV specifically among the poultry workers that worked in different poultry sectors to decrease the incidence of avian influenza through different routes. As a first line of defense, the poultry industry and appropriate higher authorities should ensure that all poultry handlers wear protective gloves. To improve avian influenza awareness, vaccination of poultry would generate a unique opportunity to do so.

In our study, $61.3 \%$ of the respondents were females, and chi-square showed that females mostly knew about avian influenza transmission. $93 \%$ of the study participants correctly answered that AIV was transmitted from animal to human in contrast an earlier study finding conducted in Cambodia reveals most of the participants did not know about AIV transmission. In our finding $48.7 \%$ of the participants were revealed human to human transmission that is in contrast to an earlier study conducted in Cambodia where all participants were answered that avian influenza might be transmitted from human to human [38]. According to a study conducted in Italy, the majority of respondents were aware of these modes of transmission [39].

Individuals in this survey had a mixed understanding that the disease can be transmitted by touching raw poultry, raw frozen poultry, and raw eggs. In terms of information about the vector of transmission, the majority of participants had sufficient knowledge that wild birds $273(91 \%)$ and poultry $269(89.7 \%)$ are the common vectors that assist in disease transmission. In our study, 83.7\% respondents were undergraduates the chi-square test indicated-a significant correlation between the risk of AIV transmission knowledge to veterinarians and butchers with higher levels of education. These findings are similar to another study conducted earlier in Italy [39].

The third part of the analysis is about the respondents' attitudes. More than half of the participants (55\%) were followed the precautionary measure like wearing of a surgical mask and while $73.3 \%$ of participants wash their hands before and after eating. The results of Chi-square showed a significant association between gender and wearing of surgical face masks and washing of hands. Similarly, earlier study results conducted in Cambodia showed that 166 (67.5\%) felt hand washing, 229 (93.1\%) said that wearing a mask is a good practice that can prevent themselves from HPAI [38]. An earlier study in Malaysia found that more than half of respondents took positive steps in response to Al, which is similar to our results [25]. In an earlier study conducted in China by Gong et al. 2014 specifically, 7061 (77.55\%) participants believed eating cooked poultry, washing hands before and after eating, clean the other related items was 
safe from Al infection [37]. Based on the intensity of documented practices, an earlier study conducted in Nepal revealed that handwashing with soap and water before and after eating has become the most common practice [40]. In short, the selected students showed good knowledge, attitude, and practices concerning avian influenza and related risky practices. Avian influenza is still endemic in Indonesia, especially in Java. Veterinarians, Butchers and Poultry workers are at higher risk of AIV transmission and infection.

\section{Study Limitations:}

There were several limitations in the study that should be listed. First, we limited our research to a single district in East Java Province. Second, we only surveyed students, who may not be representative of East Java's population. Third, our sample size was small, which may adversely affect the results' validity and reliability. Despite these limitations, we believe our results would be useful to researchers and policymakers in the future.

\section{Conclusion}

This study reports a high level of knowledge, attitudes, and practices, among students in public universities of Surabaya on avian influenza which might be helpful in the future for the precautionary role against $\mathrm{Al}$ as civilized nationals and will be helpful to significantly play role in spreading knowledge among the society.

\section{Declarations}

Funding: This study was funded from Universitas Airlangga, project number 418/UN3.15/PT/2021.

ACKNOWLEDGMENTS: The writers would like to my friends who help me a lot to translate my Questionnaire and other relevant assist. We are grateful to all of the respondents, including their family members, for their willingness to help and for their thoughtful responses.

Conflict of interest: The author reports no conflicts of interest in this work

Author (s) contributions: SR conceived the study, conducted the questionnaire, data entry, performed the statistical analysis, drafted and reviewed the manuscript. FAR, and SR conducted the questionnaires and data entry, MHE and MIK performed the statistical analysis, reviewed and drafted the manuscript. All authors read and approved the final manuscript.

\section{References}

1. Spekreijse D, Bouma A, Koch G, Stegeman JJVM. Airborne transmission of a highly pathogenic avian influenza virus strain H5N1 between groups of chickens quantified in an experimental setting. $J$ Veterinary Microbiology. 2011;152(1-2):88-95. 
2. Gilbert M, Prosser DJ, Zhang G, Artois J, Dhingra MS, Tildesley M, et al. Could Changes in the agricultural Landscape of northeastern China Have influenced the Long-distance transmission of Highly pathogenic avian influenza H5nx Viruses? 2017;4:225.

3. Li K, Xu K, Peiris J, Poon L, Yu K, Yuen K, et al. Characterization of H9 subtype influenza viruses from the ducks of southern China: a candidate for the next influenza pandemic in humans? J Journal of virology. 2003;77(12):6988-94.

4. Organization WH. H5N1 avian influenza: time-line of major events. 2009.

5. Peiris JM, De Jong MD, Guan YJCmr. Avian influenza virus (H5N1): a threat to human health. 2007;20(2):243-67.

6. Amendola A, Ranghiero A, Zanetti A, Pariani EJ. Is avian influenza virus A (H5N1) a real threat to human health. J Prev Med Hyg. 2011;52(3):107-10.

7. Loth L, Gilbert M, Wu J, Czarnecki C, Hidayat M, Xiao XJPvm. Identifying risk factors of highly pathogenic avian influenza (H5N1 subtype) in Indonesia. 2011;102(1):50-8.

8. Lam TT-Y, Hon C-C, Pybus OG, Pond SLK, Wong RT-Y, Yip C-W, et al. Evolutionary and transmission dynamics of reassortant H5N1 influenza virus in Indonesia. J PLoS Pathog. 2008;4(8):e1000130.

9. Oner AF, Bay A, Arslan S, Akdeniz H, Sahin HA, Cesur Y, et al. Avian influenza A (H5N1) infection in eastern Turkey in 2006. J New England Journal of Medicine. 2006;355(21):2179-85.

10. Lowe CJCA. Viral clouds: becoming H5N1 in Indonesia. 2010;25(4):625-49.

11. Karo-Karo D, Bodewes R, Hendra Wibawa I, Artika M, Pribadi ES, Diyantoro D, et al. Reassortments among avian influenza A (H5N1) viruses circulating in Indonesia, 2015-2016. \% J Emerging infectious diseases. 2019;25(3):465.

12. Knobler SL, Mack A, Mahmoud A, Lemon SM, editors. Strategies for Controlling Avian Influenza in Birds and Mammals. The Threat of Pandemic Influenza: Are We Ready? Workshop Summary; 2005 : National Academies Press (US).

13. Ibrahim H, Rahman NAA, Mamat S, Haque M. Knowledge, attitude, and practice toward avian flu among students in a public university in Pahang, Malaysia. J Journal of Datta Meghe Institute of Medical Sciences University. 2017;12(4):269.

14. Vivas A, Gelaye B, Aboset N, Kumie A, Berhane Y, Williams MAJJopm. Knowledge, attitudes, and practices (KAP) of hygiene among school children in Angolela, Ethiopia. J Journal of preventive medicine hygiene and Nutrition in Foodservice and Catering. 2010;51(2):73.

15. Ojulong J, Mitonga KH, lipinge SJAhs. Knowledge and attitudes of infection prevention and control among health sciences students at University of Namibia. J African health sciences. 2013;13(4):1071-8.

16. Gao H, Hu R, Yin L, Yuan X, Tang H, Luo L, et al. Knowledge, attitudes and practices of the Chinese public with respect to coronavirus disease (COVID-19): an online cross-sectional survey. BMC Public Health. 2020;20(1):1-8. 
17. Di Giuseppe G, Abbate R, Albano L, Marinelli P, Angelillo IF. A survey of knowledge, attitudes and practices towards avian influenza in an adult population of Italy. J BMC infectious diseases. 2008;8(1):1-8.

18. Ismail NA, Ahmed HA. Knowledge, attitudes and practices related to avian influenza among a rural community in Egypt. J J Egypt Public Health Assoc. 2010;85(1-2):73-96.

19. Neupane D, Khanal V, Ghimire K, Aro AR, Leppin AJBid. Knowledge, attitudes and practices related to avian influenza among poultry workers in Nepal: a cross sectional study. J BMC infectious diseases. 2012;12(1):1-7.

20. Khun M, Heng C, Kasuya H, Sakamoto JJAPjotm. Knowledge, attitudes and practices towards avian influenza A (H5N1) among Cambodian women: A cross-sectional study. 2012;5(9):727-34.

21. Maton T, Butraporn P, Kaewkangwal J, Fungladda WJSAjotm, health p. Avian influenza protection knowledge, awareness, and behaviors in a high-risk population in Suphan Buri Province, Thailand. J Southeast Asian journal of tropical medicine. 2007;38(3):560.

22. WHO. Avian and other zoonotic influenza. 2015;17 (http://www.who.int/influenza/human_animal_interface/en/) Accessed 7 May 2018., :1-81.

23. Xiang N, Shi Y, Wu J, Zhang S, Ye M, Peng Z, et al. Knowledge, attitudes and practices (KAP) relating to avian influenza in urban and rural areas of China. BMC infectious diseases. 2010;10(1):1-7.

24. Kumar SC, Ramesh N, Sreevatsan S, Joseph B, Alle P, Belani KG, et al. Knowledge, attitudes, and poultry-handling practices of poultry workers in relation to avian influenza in India. $\mathrm{J}$ Indian journal of occupational environmental medicine. 2013;17(1):16.

25. Ibrahim H, Rahman NAA, Mamat S, Haque MJJoDMloMSU. Knowledge, attitude, and practice toward avian flu among students in a public university in Pahang, Malaysia. 2017;12(4):269.

26. Zhou X, Zhang Y, Shen C, Liu A, Wang Y, Yu Q, et al. Knowledge, attitudes, and practices associated with avian influenza along the live chicken market chains in Eastern China: A cross-sectional survey in Shanghai, Anhui, and Jiangsu. 2019;66(4):1529-38.

27. Liu M-D, Chan T-C, Wan C-H, Lin H-P, Tung T-H, Hu F-C, et al. Changing risk awareness and personal protection measures for low to high pathogenic avian influenza in live-poultry markets in Taiwan, 2007 to 2012. J BMC infectious diseases. 2015;15(1):1-15.

28. Charania NA, Martin ID, Liberda EN, Meldrum R, Tsuji LJ. Bird harvesting practices and knowledge, risk perceptions, and attitudes regarding avian influenza among Canadian First Nations subsistence hunters: implications for influenza pandemic plans. BMC public health. 2014;14(1):1-11.

29. WHO WHO. Management of substance abuse. Process of translation and adaptation of instruments. 2019;Available: https://www.who.int/substance_abuse/research_tools/translation/en/. Accessed: 1 june 2020.

30. Dinh PN, Long HT, Tien NTK, Hien NT, Mai LTQ, Phong LH, et al. Risk factors for human infection with avian influenza A H5N1, Vietnam, 2004. J Emerging infectious diseases. 2006;12(12):1841.

31. Mills CE, Robins JM, Bergstrom CT, Lipsitch MJPM. Pandemic influenza: risk of multiple introductions and the need to prepare for them. PLoS Medicine. 2006;3(6):e135. 
32. Radwan GN, Wahid WYA, El-Derwy D, El-Rabat MJTJotEPHA. Knowledge, attitudes, and practices of avian influenza among backyard poultry breeders in Fayoum Governorate, Egypt. The Journal of the Egyptian Public Health Association. 2011;86(5 and 6):104-10.

33. Khan SA, Hashmi I, Ranjha AN, Yosufzai MK, Hashmi K, Anjum QJJTJotPMA. Students' cornerawareness of bird flu amongst young college students. 2008;58(8):466.

34. Maton T, Butraporn P, Kaewkangwal J, Fungladda WJSAjotm, health p. Avian influenza protection knowledge, awareness, and behaviors in a high-risk population in Suphan Buri Province, Thailand. 2007;38(3):560.

35. Somrongthong R, Beaudoin A, Bender J, Sasipreeyajan J, Laosee O, Pakinsee S, et al. Use of personal protective measures by Thai households in areas with avian influenza outbreaks. J Zoonoses public health 2012;59(5):339-46.

36. Di Giuseppe G, Abbate R, Albano L, Marinelli P, Angelillo IFJBid. A survey of knowledge, attitudes and practices towards avian influenza in an adult population of Italy. 2008;8(1):1-8.

37. Gong Z, Lv H, Ding H, Han J, Sun J, Chai C, et al. Epidemiology of the avian influenza A (H7N9) outbreak in Zhejiang Province, China. J BMC infectious diseases. 2014;14(1):1-8.

38. Khun M, Heng C, Kasuya H, Sakamoto JJAPjotm. Knowledge, attitudes and practices towards avian influenza A (H5N1) among Cambodian women: A cross-sectional study. Asian Pac J Trop Med. 2012;5(9):727-34.

39. Abbate R, Di Giuseppe G, Marinelli P, Angelillo IF. Knowledge, attitudes, and practices of avian influenza, poultry workers, Italy. Emerg Infect Dis. 2006;12(11):1762.

40. Neupane D, Khanal V, Ghimire K, Aro AR, Leppin AJBid. Knowledge, attitudes and practices related to avian influenza among poultry workers in Nepal: a cross sectional study. 2012;12(1):1-7.

\section{Figures}



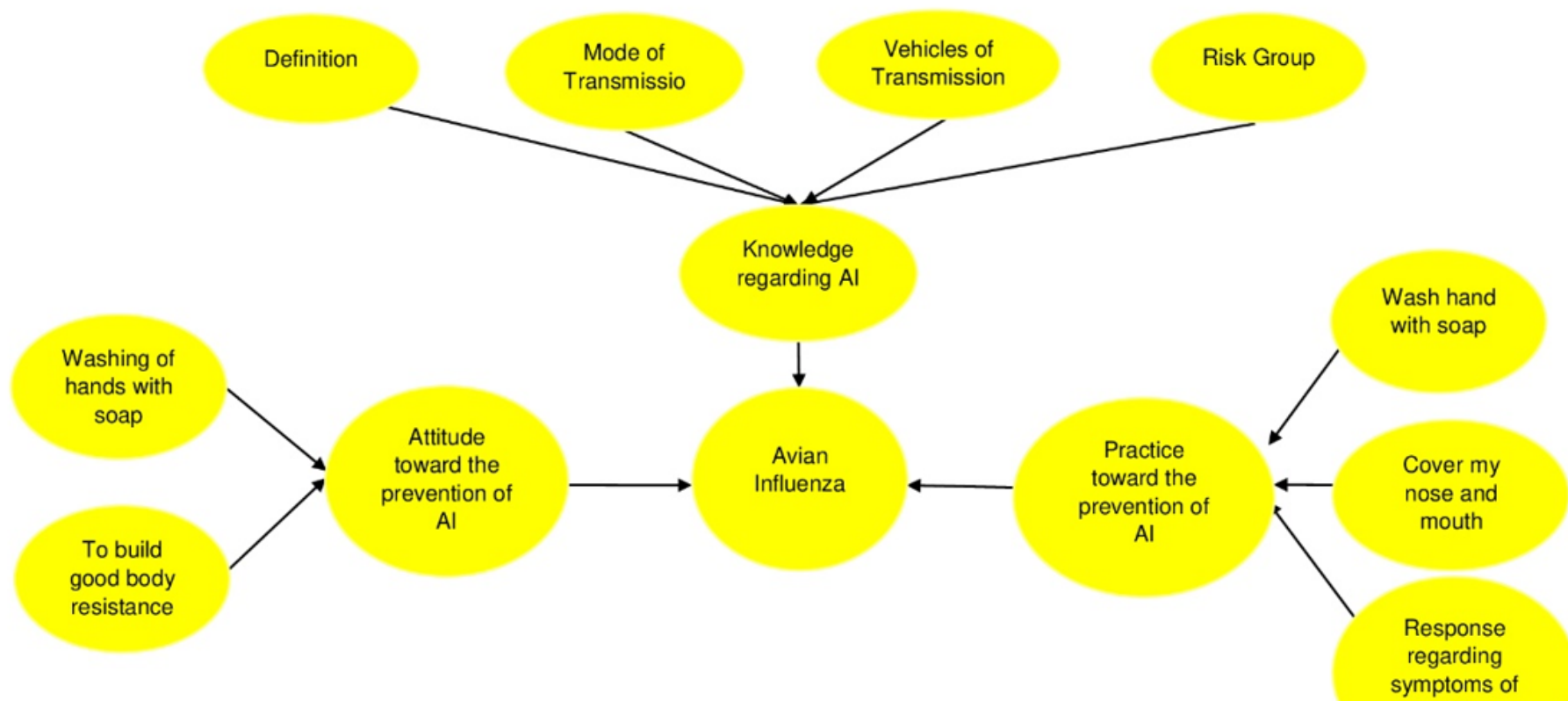

Al

\section{Figure 1}

KAP survey framework on avian influenza

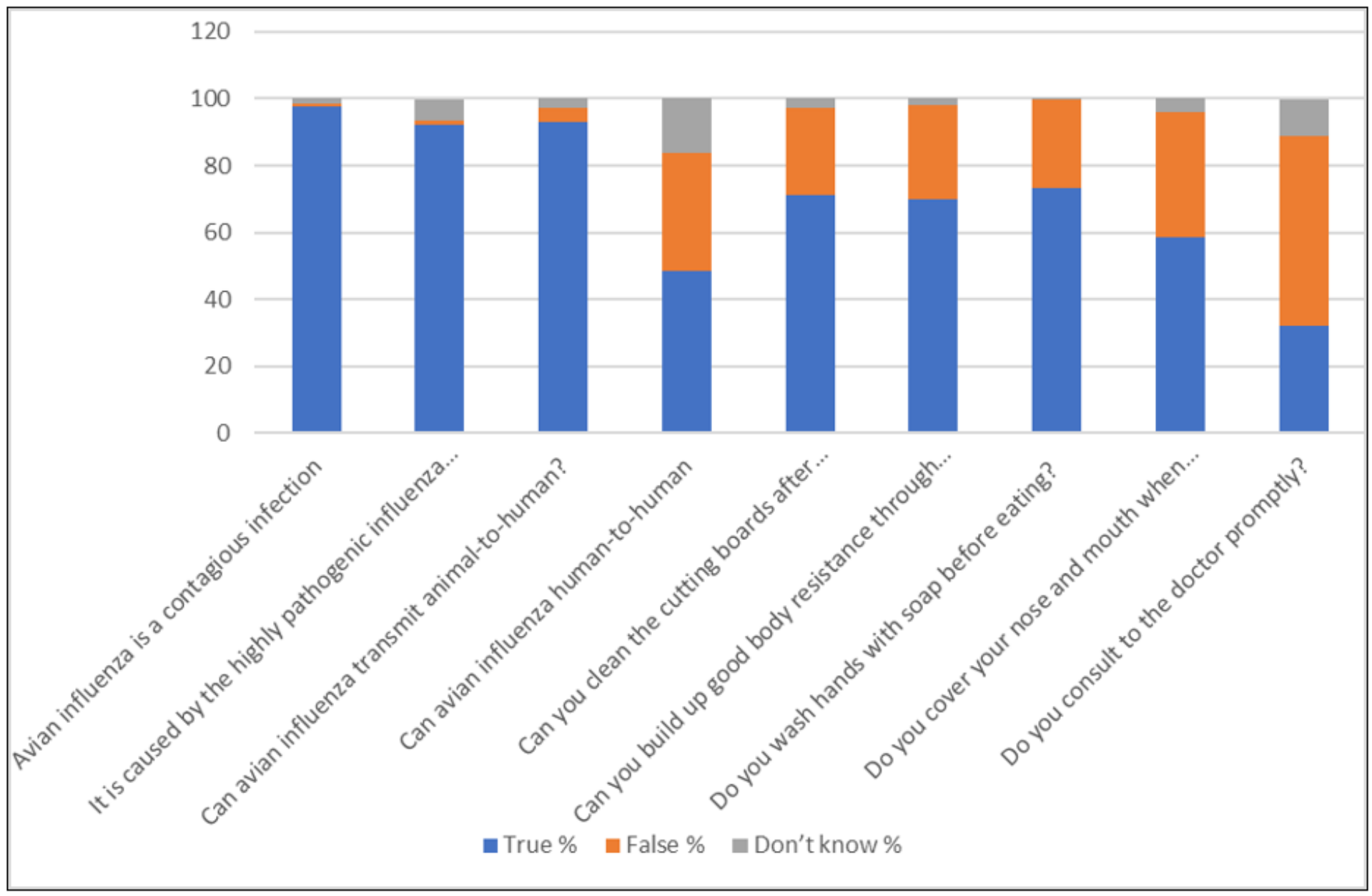


Figure 2

Responses regarding knowledge, attitude and practices 